\title{
EFFICACY OF MELOXICAM (METACAM®) AS ADJUNCT TO A BASIC THERAPY FOR THE TREATMENT OF DIARRHOEA IN CALVES
}

\author{
H. Philipp, H. Schmidt, F. Düring und E. Salamon
}

Boehringer Ingelheim Animal Health GmbH, D-55216 Ingelheim am Rhein, Germany

The objective of this placebo-controlled randomised open multi-center study was to investigate the clinical efficacy and tolerance of a single i.v. administration of the NSAID Metacam ${ }^{\circledR} 2 \%$ as adjunct to a basic therapy in young scouring calves.

Carried out by 4 investigators, the study comprised a total of 38 operations including 191 calves of both sexes. Calves were between 1 day and 10 weeks of age weighing 40 to $100 \mathrm{~kg}$. All animals showed clinical signs of diarrhoea. Clinical examination was carried out on Days 1 (prior to as well as 1 and 6-8 h post-treatment), 2 and 4 . As a basic therapy, all calves received oral electrolyte supplementation $\left(\right.$ Diakur ${ }^{\circledR}$ ) 3 times per day over 2 days, optionally also on Day 3, and gentamicin (Frieso ${ }^{\circledR}$ _Gent) $5 \mathrm{mg} / \mathrm{kg}$ b.w., s.c., and $0,4 \mathrm{mg} / \mathrm{kg}$ for optional follow-up treatment. 96 animals were allocated to the Metacam group (M) and additionally treated with meloxicam $0.5 \mathrm{mg} / \mathrm{kg}$ b.w., i.v., while 95 calves in the control group (C) received isotonic saline $(0.02 \mathrm{ml} / \mathrm{kg}$ b.w., i.m. $)$.

The primary parameters of the study were the "Clinical Diarrhoea Score" (CDS) and the "Clinical Index Score" (CIS). For each animal the CDS was calculated per examination by summing up the individual scores for dehydration, faecal consistency and signs of visceral pain (at defaecation). The CIS was calculated by addition of the scores for behaviour, feed intake and incidence of fever to the CDS. Rectal temperature, respiratory rate, heart rate, CDS and CDI were evaluated on a quantitative basis. Deviations from baseline (0 hours) were used for comparison of groups to adjust for differences between animals prior to treatment. A final assessment of clinical efficacy of the different treatment procedures completed the evaluation of the results.

The response in the primary clinical parameters, the CDS and the CIS, was significantly higher in M than in C. Statistically significant differences were found for both, the drug response over the entire study examination (expressed as AUC values using the devation from baseline) and at each individual examination.

Improvements in rectal temperature (excl. $48 \mathrm{~h}$ ), general condition, behaviour, feed intake, dehydration, signs of visceral pain, and faecal consistency (excl. $1 \mathrm{~h}$ ) were significantly more pronounced in $\mathrm{M}$ than in $\mathrm{C}$ at all time points. Additional antibiotic treatment became necessary significantly more frequently in $\mathrm{C}$ than in $\mathrm{M}$; consequently, the final assessment of clinical efficacy ("good" or "excellent") was significantly different between groups in favour of M. One calf treated with Metacam showed a transient local swelling 1 day following injection.

It is concluded from this study that a single meloxicam dose of $0.5 \mathrm{mg} / \mathrm{kg}$ b.w., i.v., in combination with a basic therapy is significantly more effective than the basic therapy alone in calves suffering from diarrhoea. 